\title{
Specific Inhibition of Mouse Oocyte Nuclear Protein Phosphatase-1 Stimulates Germinal Vesicle Breakdown
}

\author{
JASON E. SWAIN, ${ }^{1,2,5}$ XIA WANG,${ }^{1,3,5}$ THOMAS L. SAUNDERS,,${ }^{4,5}$ RODNEY DUNN, ${ }^{3}$ \\ AND GARY D. SMITH ${ }^{1,2,3,5}$ * \\ ${ }^{1}$ Department of Obstetrics and Gynecology, University of Michigan, Ann Arbor, Michigan \\ ${ }^{2}$ Department of Physiology, University of Michigan, Ann Arbor, Michigan \\ ${ }^{3}$ Department of Urology, University of Michigan, Ann Arbor, Michigan \\ ${ }^{4}$ Department of Internal Medicine, University of Michigan, Ann Arbor, Michigan \\ ${ }^{5}$ Reproductive Sciences Program, University of Michigan, Ann Arbor, Michigan
}

\begin{abstract}
Okadaic acid (OA)-induced germinal vesicle breakdown (GVBD) and localization of protein phosphatase-1 (PP1) in oocyte nuclei are suggestive of PP1's role in regulating oocyte GVBD. To explore this possibility, we microinjected protein phosphatase (PP) inhibitors OA, anti-PP1 antibody (anti-PP1), PP1 inhibitor 12, and anti-PP2A antibody (anti-PP2A) into nuclei of roscovitine (ROSC)-arrested mouse oocytes. Oocytes were also injected with recombinant PP1 in the absence of ROSC. Oocytes were assessed for GVBD and metaphase II (MII) development at 2 and $18 \mathrm{hr}$ post-injection. Data were analyzed using Cochran-Mantel-Haenszel Statistics adjusted for time. Microinjection of OA significantly enhanced GVBD in comparison to controls at 2 and $18 \mathrm{hr}(P<0.01)$, yet had no effect on MII development. Similarly, microinjection of anti-PP1 resulted in significantly higher levels of GVBD compared to controls at 2 and $18 \mathrm{hr}$ $(P<0.01)$. Interestingly, anti-PP1 microinjection also tended to enhance MII development at $18 \mathrm{hr}$ in comparison to controls $(P<0.09)$. Microinjection of 12 , anti-PP2A, and PP1 had no effect on GVBD or MII development. If reduction of PP1 activity was important for GVBD, one would anticipate an endogenous means of regulating PP1 activity at this developmental stage. In somatic cells, phosphorylation of PP1 at Thr 320 causes PP1 inactivation. Germinal vesicle-intact oocytes did not contain phosphorylated PP1, as determined using a specific Thr320-Phospho-PP1 antibody, Western blot analysis, and confocal immunocytochemistry. At or around the time of GVBD, oocyte PP1 became phosphorylated at Thr320, which remained phosphorylated through MII development. These data indicate that inhibition of intra-nuclear PP1, through specific antibody neutralization, mimics OA-stimulated GVBD, providing the first direct evidence that nuclear PP1 is involved in regulation of oocyte nuclear membrane integrity. In addition, phosphorylation of PP1 occurs at/or around GVBD indicating that inactivation of PP1 is an important intracellular event in regulation of nuclear envelope dissolution at GVBD. Mol. Reprod. Dev. 65: 96-103, 2003. ๑ 2003 Wiley-Liss, Inc.
\end{abstract}

Key Words: nuclear lamins; roscovitine; okadaic acid; MPF

\section{INTRODUCTION}

Elucidating regulatory mechanisms involved in oocyte meiosis is imperative to fully understand this complex process and allow for optimization of in vitro maturation systems. Mouse oocytes spontaneously resume meiosis once removed from their follicular environment (Pincus and Enzmann, 1935). This process involves the oocyte leaving a state of quiescence at prophase of meiosis I, undergoing dissolution of the nuclear envelope (NE) in a process known as germinal vesicle breakdown (GVBD), and finally re-arresting at metaphase of meiosis II until fertilization. These oocytes are referred to as meiotically competent. Release of the oocyte from its quiescent state, as well as other processes in cell cycle progression, is regulated by intracellular phosphorylation/dephosphorylation events. Numerous kinases have been investigated and implicated in oocyte meiotic regulation, while the role of specific protein phosphatases (PP) has largely been overlooked. Two specific kinases, mitogen-activated protein kinase (MAPK) and maturation promoting factor (MPF) have been studied extensively (reviewed by Abrieu et al., 2001). Maturation promoting factor consists of two subunits, cyclin B and p34 ${ }^{\text {cdc2 }}$ kinase (Labbe et al., 1989). Through a series of phosphorylation events, MPF activation leads to GVBD and completion of meiosis I (Maller, 1993). In meiotically competent oocytes, MPF's p34 ${ }^{\text {cdc2 }}$ kinase and cyclin B are predominantly localized within nuclei (Mitra and Schultz, 1996). Inhibition of MPF with the pharmacological inhibitor roscovitine

\footnotetext{
Grant sponsor: NIH; Grant number: HD35125-01A1.

*Correspondence to: Dr. Gary D. Smith, 6428 Medical Sciences Building I, 1150 W Medical Center Dr., Ann Arbor, MI 48109-0617. E-mail: smithgd@umich.edu

Received 2 September 2002; Accepted 22 November 2002

Published online in Wiley InterScience (www.interscience.wiley.com) DOI $10.1002 / \mathrm{mrd} .10258$
} 
(ROSC) can block mouse oocyte GVBD (Mermillod et al., 2000).

Serine threonine PPs, which remove phosphate from phosphoproteins, thus antagonizing protein kinases, are also implicated in regulating meiosis (Rime et al., 1990; Gavin et al., 1991; Schwartz and Schultz, 1991; Smith et al., 1998a,b). Of the four types of serine/ threonine PPs that exist (PP1, PP2A, PP2B, and PP2C; Ingebritsen and Cohen, 1983; Cohen, 1989), two specific PP's, protein phosphatase-1 (PP1) and PP2A, have been observed in Xenopus (Rime et al., 1990), starfish (Picard et al., 1989), and mouse (Smith et al., 1998a) oocytes. Immunocytochemical studies have shown PP1 to be localized to the nucleus of mouse and monkey oocytes following acquisition of meiotic competence, while PP2A is predominantly cytoplasmic (Smith et al., 1998a,b). An important discovery in phophatase research was identification of the cell-permeable inhibitor of PP1 and PP2A, okadaic acid (OA; Bialojan et al., 1988). Oocyte microinjection or culture with OA causes premature GVBD in oocytes of several species including starfish (Picard et al., 1989), Xenopus (Rime et al., 1990; Goris et al., 1989), monkey (Smith et al., 1998b), and mouse (Alexander et al., 1991). Constant exposure of oocytes to OA results in severe cytoplasmic and spindle aberrations and blocks progression to MII (Rime et al., 1990; Gavin et al., 1991; Lu et al., 2002), while transient exposure to induce GVBD is compatible with normal oocyte development and fertilization (Smith et al., 1998b). Collectively, this would indicate that inhibition of a PP can stimulate GVBD, but some PP activity is necessary for meiotic progression to MII. However, the specific roles of $\mathrm{PP} 1$ and $\mathrm{PP} 2 \mathrm{~A}$ in oocytes remain unknown.

Meiotic resumption involves oocyte NE dissolution at GVBD. The NE consists of a network of filament-type proteins known as nuclear lamins (Stuurman et al., 1998). The three major constituents of the nuclear lamina are A, B, and C type lamins (Eggart et al., 1993). Nuclear lamina have been characterized in amphibian and vertebrate oocytes (Krohne et al., 1981; Schatten et al., 1985; Maul et al., 1987) and mouse oocytes contain all three lamins (Schatten et al., 1985; Maul et al., 1987; Houliston et al., 1988). Nuclear envelope integrity is controlled through phosphorylation and dephosphorylation of nuclear lamins. Hypo-phosphorylation of nuclear lamins maintains NE integrity, while hyperphosphorylation of lamins results in NE disassembly (Stuurman et al., 1998). In somatic cells, PP1 is involved in lamin-B dephosphorylation (Thompson et al., 1997), while protein kinase C (PKC; Goss et al., 1994; Thompson and Fields, 1996) and possibly p34 ${ }^{\text {cdc2 }}$ kinase are responsible for phosphorylation of lamin-B (Nikolakaki et al., 1997). A complex containing p34 $4^{\text {cdc2 }}$ kinase and cyclin B, similar to MPF, is implicated in disassembly of clam oocyte NE (Dessev et al., 1991). Thus, in mitotic cells, it appears that NE integrity is determined through protein kinase and PP interactions and balance of these enzymes in regulating the phosphorylation of NE phosphoproteins. However, components regulating $\mathrm{NE}$ integrity during meiosis remain to be identified.

Intracellular mechanisms regulating PP1 and PP2A are numerous and diverse. In cell-free extracts PP1, but not PP2A, is sensitive to nanomolar concentrations of cytoplasmic inhibitors I1 and I2 (Ingebritsen and Cohen, 1983). Inactivation of PP1 by I1 involves I1 phosphorylation by protein kinase-A (Endo et al., 1996), whereas I2 does not require phosphorylation. In addition, it has been demonstrated that cdc2 kinase phosphorylation of PP1 on Thr320 causes PP1 inactivation (Dohadwala et al., 1994; Kwon et al., 1997). To date, the regulation of PP1 in the oocyte has not been determined.

The objectives of this study where to determine which OA sensitive PP, PP1, and/or PP2A, is involved in regulating $\mathrm{NE}$ dissolution during oocyte $\mathrm{GVBD}$, and to elucidate mechanisms involved in regulating oocyte $\mathrm{PP}$ activity at/or around the time of GVBD.

\section{MATERIALS AND METHODS}

\section{Mouse Stimulation and Oocyte Collection}

Female CF1 mice (Harlan; Indianapolis, IN) 1923 days old were injected with 10 IU eCG (Sigma; St. Louis, MO). Fully-grown GVBD-competent oocytes were collected $42-44 \mathrm{hr}$ post-eCG injection. These GVI oocytes were isolated by manual rupturing of antral ovarian follicles in Hepes-buffered Human Tubal Fluid medium (Quinn et al., 1985; Irvine Scientific, Santa Ana, CA) supplemented with $0.3 \% \mathrm{w} / \mathrm{v}$ polyvinylpyrrolidone (Sigma; HTFH+PVP). In some experiments, oocytes were cultured in Human Tubal Fluid medium (HTF; Irvine Scientific) supplemented with PVP for 2, 7, and $16 \mathrm{hr}$ following $\mathrm{GV}$-intact oocyte collection to isolate GVBD, MI, and MII oocytes, respectively.

\section{Roscovitine Dose Titration}

Oocytes were denuded through repeated mouth pipetting with hand-pulled pipettes of decreasing diameters $(\sim 200$ thru $90 \mu \mathrm{m})$ and placed into organ culture wells in groups of 20-30/900 $\mu \mathrm{l}$ of HTF supplemented with $3 \mathrm{mg} /$ $\mathrm{ml}$ fraction V BSA (FisherBiotech; Fair Lawn, NJ) and 0, 6.25, 12.5, 25, or $50 \mu \mathrm{M}$ ROSC (BioMol, Plymouth Meeting, PA). Oocytes were cultured in $5 \% \mathrm{CO}_{2}$ in air at $37^{\circ} \mathrm{C}$ and assessed for stage of nuclear maturation at $400 \times$ on an inverted microscope with Hoffman optics after $2,4,6$, and $18 \mathrm{hr}$ of culture. This experiment was performed to determine a dose of ROSC that would allow 40-60\% GVBD during $16 \mathrm{hr}$-culture. This tempering of spontaneous GVBD was essential to determine if inhibition of PP1 and/or PP2A stimulates mouse oocyte GVBD.

\section{Oocyte Germinal Vesicle Microinjection}

Oocytes were collected as described above and placed into $\mathrm{HTFH}+\mathrm{PVP}$ medium supplemented with $50 \mu \mathrm{M}$ ROSC for microinjection. Oocytes were microinjected on a Nikon inverted microscope with Hoffman optics equipped with Narishige micromanipulators and a Tritech 
microinjector (Mager Scientific, Dexter, MI). Oocyte GV were injected at $400 \times$ magnification with $\sim 8 \rho \mathrm{l}$ of $1 \mu \mathrm{M}$ OA (Calbiochem; San Diego, CA), $1 \mu$ M I2 (BioMol), 1 mM anti-PP1 antibody (Upstate Biotechnology, Lake Placid) and $1 \mathrm{mM}$ anti-PP2A antibody (Upstate Biotechnology). The microinjected volumes were confirmed as previously described (Corson and Fein, 1983). Controls for each chemical treatment included buffer injection and no injection.

Microinjected and control oocytes were placed into organ culture wells containing $900 \mu \mathrm{l}$ HTF medium supplemented with $0.3 \% \mathrm{BSA}$ and $50 \mu \mathrm{M}$ ROSC and cultured as described above. Oocytes were assessed for stage of nuclear maturation at 2 and $18 \mathrm{hr}$ post-injection at $400 \times$ on an inverted microscope. Recombinant PP1 (1mM; Upstate) was also injected into oocyte nuclei in the absence of ROSC and cultured to assess effects on nuclear maturation at 2 and $18 \mathrm{hr}$ post-injection.

\section{Electrophoresis and Western Blot Analysis}

Two hundred frozen cumulus cell-free fully grown GV-intact, GVBD, MI, or MII oocytes were thawed in prewarmed $2 \times$ SDS-PAGE sample loading buffer (80 mM Tris-HCl [pH =6.8], $20 \%$ glycerol, $4 \%$ SDS, $4 \%$ $\beta$-mercaptoethanol, $0.04 \%$ bromophenol blue), vortexed and placed on ice for $15 \mathrm{~min}$. Following sonication on ice, samples were denatured at $90^{\circ} \mathrm{C}$ for $10 \mathrm{~min}$ and placed on ice for $5 \mathrm{~min}$. Samples were stored at $-20^{\circ} \mathrm{C}$ until electrophoresis was performed.

Total protein from two hundred mouse oocytes was loaded in each lane and separated by one-dimensional SDS-PAGE. Resolving gels were cast using $12 \%$ acrylamide; stacking gels contained 5\% acrylamide. Approximately $5 \mu \mathrm{g}$ of cdc2 phosphorylated PP1 HeLa cell lysate (Cell Signaling Technology Inc., Beverly, MA) was used as a positive control for recognizing PP1 and Phospho-PP1. Gels were equilibrated and transferred to Hybond-P PVDF transfer membrane (Amersham Life Science, Little Chalfont Buckinghamshire, England) by Semi-Dry Electrophoretic Transfer (Bio-Rad Laboratories, Hercules, CA). Blots were blocked in 5\% nonfat milk in TBST at room temperature for $1 \mathrm{hr}$ and incubated with anti-phospho-PP1 (Thr320; diluted 1:1000, Cell Signaling Technology Inc.) antibody in TBST plus $5 \%$ nonfat milk overnight at $4{ }^{\circ} \mathrm{C}$ with agitation. After complete washing in TBST, blots were incubated with anti-rabbit horseradish peroxidaseconjugated IgG (diluted 1:10,000) at room temperature for $1 \mathrm{hr}$, washed in TBST, and developed with ECL Plus reagents (Amersham Life Sciences, Buckinghamshire, UK).

To investigate expression of PP1, blots were stripped for $30 \mathrm{~min}$ at $50^{\circ} \mathrm{C}$ water bath with agitation in a stripping buffer (62.5 mM Tris-HCl [pH 6.7], $100 \mathrm{mM}$ $\beta$-mercaptoethanol, and $2 \%$ SDS). Completely stripped blots were blocked in 5\% nonfat milk in TBST for $1 \mathrm{hr}$ at room temperature, then incubated with anti-PP1 antibody (diluted 1:1,000, a gift from Dr. Angus Nairn, Rockefeller University) overnight at $4^{\circ} \mathrm{C}$ with agitation and processed further as described above.

\section{Immunocytochemistry and Confocal Microscope Analysis}

In order to identify the localization on PP1 and phospho-PP1 during meiotic resumption, GV-intact and GVBD oocytes were collected, attached to polylysine coated coverslips, and fixed in $2 \%$ (wt/vol) paraformaldehyde with $0.04 \%$ (v/v) Triton X-100. Oocytes were then blocked overnight with $0.3 \%$ (w/v) BSA in PBS at $4^{\circ} \mathrm{C}$, and incubated with anti-PP1 antibody at a 1:200 dilution or a polyclonal anti-phospho-PP1 $\alpha$ antibody at a 1:50 dilution for $1 \mathrm{hr}$ at $37^{\circ} \mathrm{C}$. After washing with $0.3 \%$ $\mathrm{BSA}+0.1 \%(\mathrm{v} / \mathrm{v})$ Tween-20 in PBS, oocytes were incubated in the same wash buffer for $90 \mathrm{~min}$ at $37^{\circ} \mathrm{C}$. Samples were then reacted with anti-rabbit Alexa 488conjugated secondary antibody (Molecular Probes, Eugene, OR) at a $1: 1,000$ dilution for $1 \mathrm{hr}$ at $37^{\circ} \mathrm{C}$. Following washing, slides were incubated with $5 \mu \mathrm{g} / \mathrm{ml}$ propidium iodide (PI) in PBS containing $0.1 \%(\mathrm{w} / \mathrm{v}) \mathrm{BSA}$ for $20 \mathrm{~min}$ at $37^{\circ} \mathrm{C}$. Coverslips were then mounted on glass slides with $90 \%$ glycerol in PBS for fluorescence microscopic visualization with a Bio-Rad MRC-600 confocal scanning laser microscope.

\section{Statistical Analysis}

In ROSC dose-response experiments, data were collected over six replicates and analyzed using Fisher's Exact test. Microinjection data were collected over three to four replicates for each treatment and GVBD data were analyzed using Cochran-Mantel-Haenszel Statistics adjusted for time. Metaphase II development data were analyzed using Mantel-Haenszel Chi-Square. Differences were considered significant at $P<0.05$.

\section{RESULTS}

In initial experimentation, we determined a dose of ROSC that would partially inhibit GVBD in mouse oocytes. This was important for subsequent microinjection experiments examining effects of various PP inhibitors on GVBD. Under normal circumstances, a very high percentage of mouse oocytes spontaneously resume meiosis and undergo GVBD. To determine if PP inhibition stimulated GVBD, a tempering of spontaneous GVBD was necessary. The goal was to establish a minimal dose of ROSC that would partially inhibit the population's ability to undergo GVBD without complete inhibition. Culturing oocytes in $6.25 \mu \mathrm{M}$ ROSC did not significantly alter GVBD compared to controls at any time point (Fig. 1). Culture of mouse oocytes in presence of $12.5,25$, and $50 \mu \mathrm{M}$ roscovitine significantly inhibited GVBD compared to controls at all time points examined $(P<0.05$; Fig. 1$)$. The presence of $12.5 \mu \mathrm{M}$ ROSC did not alter GVBD compared to oocytes cultured in the presence of $6.25 \mu \mathrm{M}$ ROSC at any time point examined (Fig. 1). Culture in the presence of $25 \mu \mathrm{M}$ significantly prevented GVBD more than culture in 6.25 and $12.5 \mu \mathrm{M}$ ROSC at all time points $(P<0.05$; Fig. 1$)$. Addition of $50 \mu \mathrm{M}$ ROSC to oocyte culture media significantly decreased GVBD compared to all other treatments at all time points examined $(P<0.05$; Fig. 1$)$. The $50-\mu \mathrm{M}$ 


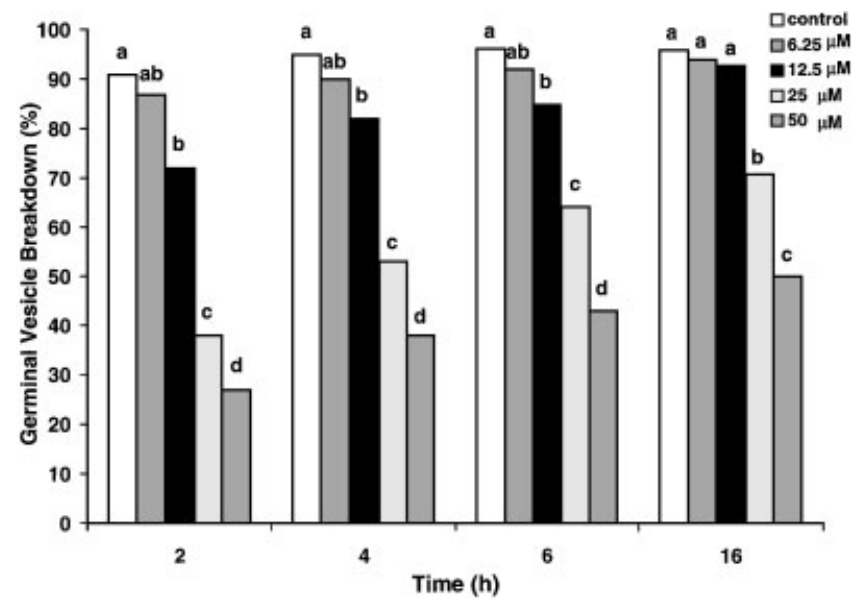

Fig. 1. Roscovitine (ROSC) dose titration and effects on germinal vesicle breakdown of mouse oocytes cultured for $2,4,6$, and $18 \mathrm{hr}$. Doses of ROSC and number of oocytes evaluated in each treatment were 0 (control; $\mathrm{n}=139), 6.25(\mathrm{n}=142), 12.5(\mathrm{n}=127), 25(\mathrm{n}=141)$, and $50 \mu \mathrm{M}$ $(\mathrm{n}=153)$. Different superscripts between treatments, within a time point, are significantly different $(P<0.05)$.

dose of ROSC permitted between 30 and $50 \%$ of oocytes to spontaneously resume meiosis within 2 to $16 \mathrm{hr}$ of culture, respectively. Based on these data, we chose a dose of $50 \mu \mathrm{M}$ for subsequent microinjection experiments.

Microinjection of OA, an inhibitor of both PP1 and PP2A, into GV of ROSC-arrested oocytes significantly enhanced GVBD in comparison to controls at 2 and $18 \mathrm{hr}$ post injection. ( $2 \mathrm{hr}$ : OA-73\%, buffer-41\%, no injection$40 \%$; $18 \mathrm{hr}$ : OA-85\%, buffer-49\%, no injection- $61 \%$; $P<0.01$; Fig. 2a). Even though OA GV-microinjection of ROSC-arrested oocytes stimulated GVBD, it had no significant effect on MII development at $18 \mathrm{hr}$ (OA$\mathrm{n}=39,38 \%$; buffer- $\mathrm{n}=39,38 \%$; no injection- $\mathrm{n}=75$, $40 \%)$.

Similar to OA injection, anti-PP1 antibody microinjection into GV of ROSC arrested ooyctes significantly increased GVBD at 2 and $18 \mathrm{hr}$ post-injection $(2 \mathrm{hr}$ : antiPP1-59\%, buffer-40\%, no injection-35\%; $18 \mathrm{hr}$ : anti-PP1$71 \%$, buffer-56\%, no injection-50\%; $P<0.01$; Fig. $2 \mathrm{~b}$ ). Interestingly, microinjection of anti-PP1 antibody into oocytes tended to enhance MII development at $18 \mathrm{hr}$ (anti-PP1-51\%, buffer-32\%, no injection-32\%; $P<0.09$ ).

Microinjection of the PP1 cytoplasmic inhibitor, I2, had no effect on GVBD compared to controls ( $2 \mathrm{hr}$ : I2$\mathrm{n}=77,54 \%$; buffer-n $=42,50 \%$; no injection- $\mathrm{n}=59$, 53\%; 18 hr: I2-79\%, buffer-69\%, no injection-66\%; Fig. 3). Similarly, I2 microinjection into ROSC arrested oocytes had no effect on MII development (I2-33\%, buffer-36\%, no injection-36\%).

To verify PP1 was indeed the PP responsible for maintaining NE integrity, anti-PP2A was also microinjected into ROSC-arrested oocytes. Germinal vesiclemicroinjection of anti-PP2A into ROSC arrested oocytes had no effect on GVBD at 2 or $18 \mathrm{hr}$ (2 hr: anti-PP2A-58\% buffer-57\%, no injection-59\%; $18 \mathrm{hr}$ : anti-PP2A-76\%, buffer-74\%, no injection-73\%; Fig. 3) or MII develop-
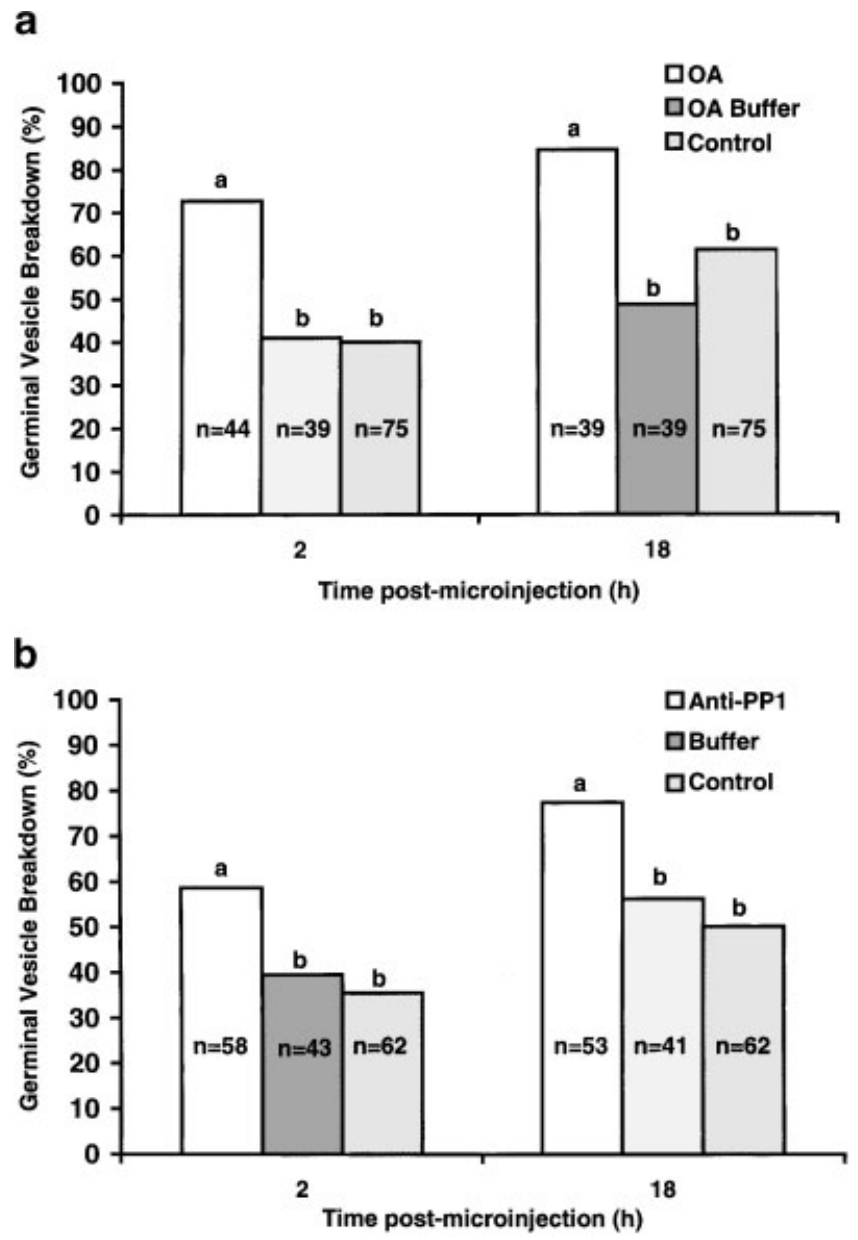

Fig. 2. Effect of nuclear microinjection of the phosphatase inhibitor (a) okadaic acid (OA) and (b) anti-PP1 antibodies (Anti-PP1) on mouse oocyte germinal vesicle breakdown (GVBD) in the presence of the specific MPF inhibitor, roscovitine. $\mathrm{n}=$ number of oocytes assessed in each treatment. Different superscripts between microinjection treatments, within a time point, are significantly different $(P<0.01)$.

ment at $18 \mathrm{hr}$ post-injection (anti-PP2A-36\%, buffer$42 \%$, no injection- $42 \%$ ).

Finally, we wished to determine if microinjection of purified recombinant PP1 into nonROSC-arrested oocyte GV could prevent GVBD. Microinjection of PP1 had no effect on GVBD at $2 \mathrm{hr}$ (PP1-n $=32,76 \%$; buffer$\mathrm{n}=35,80 \%$; no injection- $\mathrm{n}=30,77 \%$ ) or MII development at $18 \mathrm{hr}$ post-injection (PP1-59\%, buffer-61\%, no injection-60\%).

Due to the lack of effect on GVBD of microinjection of recombinant PP1, we decided to perform Western blot analysis, followed by immunocytochemistry and confocal image analysis to determine whether the phosphorylated state, and therefore, the activity of PP1, varies during oocyte maturation. Western blot analysis showed the presence of PP1 in GV-intact, GVBD, MI, and MII stage oocytes. However, phosphorylated PP1 was only present following GVBD (Fig. 4). Confocal image analysis verified the presence of PP1 in the GVintact mouse oocyte, while phosphorylated PP1 was 


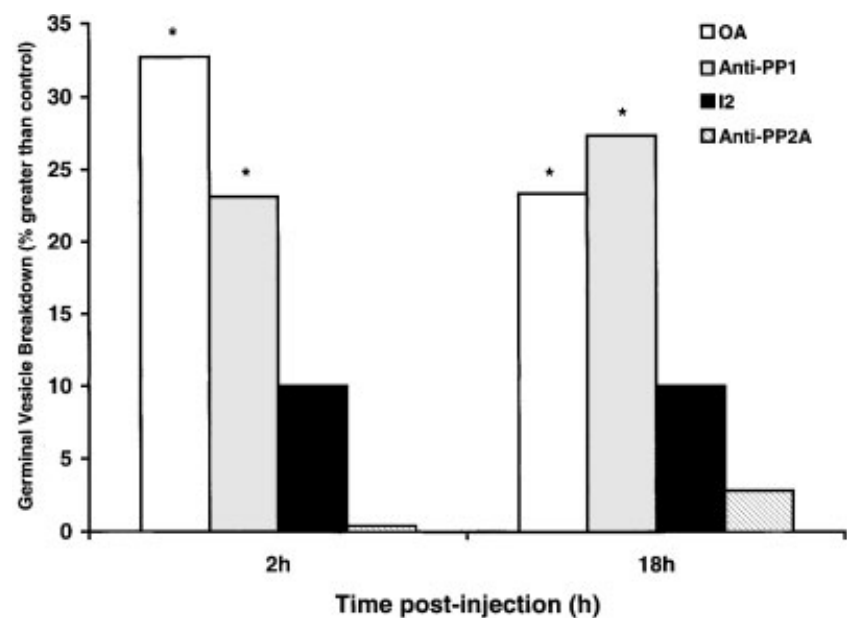

Fig. 3. Effect of nuclear microinjection of (a) OA, (b) anti-PP1, (c) inhibitor I2, and (d) anti-PP2A antibodies (Anti-PP2A) on GVBD of mouse oocytes cultured in the presence of the specific MPF inhibitor, roscovitine. Graph displays percent GVBD greater than control (vehicle injected). * Represent significant differences between treatments and vehicle injected, within a time point $(P<0.01)$.

absent. The presence of phosphorylated PP1 in GVBD oocytes was confirmed through immunocytochemistry and confocal image analysis (Fig. 5).

\section{DISCUSSION}

A large majority of mouse oocytes spontaneously resume meiosis when removed from their follicular environment, making it difficult to detect treatmentenhanced rates of GVBD. Therefore, when assessing

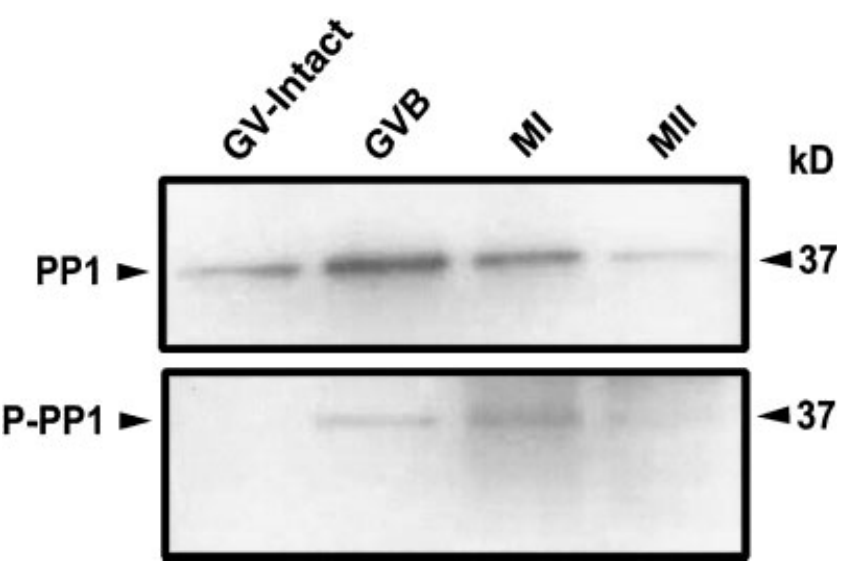

Fig. 4. Representative immunoblot of protein phosphatase-1 (PP1) and phosphorylated PP1 (Phospho-Thr320-PP1) in mouse oocytes at various stages of meiotic maturation. Lane 1: germinal vesicleintact (GV-intact, time of collection) oocytes, lane 2: oocytes that underwent germinal vesicle breakdown (GVBD; $2 \mathrm{hr}$ post-collection), lane 3: oocytes developed to metaphase I (MI; $7 \mathrm{hr}$ post-collection), and lane 4: oocytes developed to metaphase II (MII; $16 \mathrm{hr}$ post-collection). Total protein from oocytes was loaded into each lane. The blot was incubated with a polyclonal anti-PP1 antibody to show unphosporylated, or active PP1 (top panel). In addition blots were incubated with a polyclonal anti-Phospho-Thr320-PP1 antibody to show inactive PP1 (bottom panel). This experiment was performed in duplicate. factors that stimulate GVBD, it is helpful to control the event by chemical inhibition. Through ROSC treatment, it was possible to modulate the number of oocytes undergoing GVBD, without completely or irreversibly inhibiting the system. By using ROSC at a dose of $50 \mu \mathrm{M}$, mouse oocyte GVBD was held at intermediate levels, which allowed for manipulation of the system, as well as detection of increased oocyte GVBD due to chemical manipulation. It is important to realize that mechanisms of ROSC inhibition, and possible interaction with PP's, were not the focus of these experiments. This ROSC treatment was designed as a model system, or a means to an end, in attempting to elucidate which PP, $\mathrm{PP} 1$, or PP2A is involved in regulating the event of GVBD during meiosis.

Inhibition of GVBD by ROSC was successfully overcome through GV microinjection of both OA and neutralizing PP1 antibodies, but not anti-PP2A antibodies. This suggests that PP1 may be the antagonistic phosphatase to MPF's cdc2 kinase, responsible for regulating the phosphorylated state of nuclear lamins and maintenance of NE integrity. Microinjection or culture of oocytes in OA can overcome meiotic inhibition caused by chemical treatments such as cycloheximide (Gavin et al. 1991), 6-DMAP and IBMX (Kalous et al., 1993). These meiotic inhibitors are believed to interfere with meiotic resumption upstream of MPF through inhibition of protein synthesis (cyclin B) or alteration of cAMP levels. These upstream interruptions may have effects on other regulators of oocyte meiotic progression, thus making it difficult to draw any conclusions on interactions of MPF and protein phosphatases. Our results indicate GV microinjection of OA can also overcome meiotic inhibition by ROSC. Roscovitine inhibits meiotic resumption directly through MPF's $\mathrm{p} 34^{\text {cdc2 }}$ kinase by occupying the ATP binding site of ${ }^{\text {cdc2 }}$ kinase (Mermillod et al., 2000). Through antibody neutralization of oocyte nuclear PP1, under specific inactivation of MPF, our data suggests $\mathrm{PP} 1$ is the OA-sensitive PP responsible for maintaining $\mathrm{NE}$ integrity. With this said, it is not implied that protein kinases do not also play an important regulatory role in maintenance of NE integrity. We would suggest that both MPF and PP1 are important in regulating the phosphorylated state of nuclear phosphoproteins, like lamins, that ultimately influence NE integrity. This theory is further supported by studies showing MPF subunits, ${ }^{\text {cdc2 }}$ kinase and cyclin B, predominately localized in mouse (Mitra and Schultz, 1996) and starfish (Ookata et al., 1992) oocyte nuclei. Maturation promoting factor moves into nuclei of mouse oocytes in conjunction with acquisition of meiotic competence (Mitra and Schultz, 1996). In starfish oocytes, MPF traffics to the nucleus prior to resumption of meiosis (Ookata et al., 1992). PP-1 also translocates from the cytoplasm to the nucleus in conjunction with acquisition of meiotic competence (Smith et al., 1998a). In addition, immunolocalization studies show PP1 translocates to the nucleus of mitotic cells during the G2 phase (Fernandez et al., 1992) prior to the mitotic G2/M phase transition. Thus, both MPF and PP1 are present in 

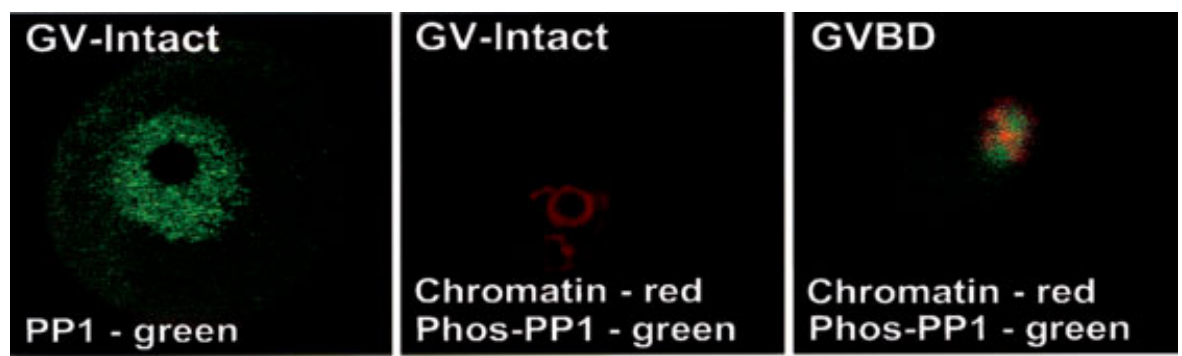

Fig. 5. Representative confocal immunofluorescent micrograph displaying localization of PP1, Phospho-Thr320-PP1, and chromatin in GV-intact and oocyte that have undergone GVBD. The left panel shows presence of PP1 (green) in GV-intact oocytes, while the center panel shows chromatin, stained in red, and lack of phosphorylated PP1 (no green). The right panel shows presence of PhosphoThr320-PP1 (green) in association with chromatin (red) in oocytes that have undergone GVBD.

the nucleus at a time when they can regulate phosphorylation of nuclear phosphoproteins important for maintaining NE integrity or stimulating NE dissolution and GVBD.

In somatic cells, trafficking of PP1 to the NE is required for assembly of nuclear lamins (Steen et al., 2000). PP-1 anchoring protein(s) exist within the assembling mitotic NE and are requisite for NE reassembly (Steen et al., 2000). Specific inhibition of PP1 in mitotic cells demonstrates that this OA-sensitive PP is the major serine/threonine PP responsible for dephosphorylation of lamin-B, a process necessary for $\mathrm{NE}$ re-assembly and maintenance of NE integrity (Thompson et al., 1997). Dephosphorylation of lamin-B by purified PP1 allows re-assembly of lamina polymers (Peter et al., 1991). It has also been shown that p3 $4^{\text {cdc2 }}$ kinase acts directly on lamin-B receptors to cause hyperphosphorylation in mitotic cells (Nikolakaki et al., 1997) and evidence exists to suggest MPF is involved in NE disassembly in clam oocytes (Dessev et al., 1991). These findings suggest that PP1 and MPF likely regulate phosphorylation of $\mathrm{NE}$-associated proteins and dictate the integrity of the NE during mitosis and meiosis.

Monkey oocytes transiently exposed to low concentrations of OA have increased rates of MII development compared to control treatments (Smith et al., 1998b), primarily due to enhanced meiotic initiation. However, prolonged exposure of oocytes to OA results in severe cytoplasmic aberrations (Smith et al., 1998b) and microtubule abnormalities (Alexander et al., 1991). These observations, coupled with those indicating PP2A is associated with cytoskeletal elements such as microtubules, centromeres, and spindles (Van Dolah and Ramsdell, 1992; Sontag et al., 1995; Tournebize et al., 1997; Lu et al., 2002) suggests PP2A involvement with microtubule polymerization, chromatin segregation, and completion of meiosis. Oocytes injected with antiPP1 antibodies showed higher rates of MII development compared to OA injected even though they had comparable GVBD rates. This is likely due to inhibitory effects of OA exposure on PP2A and compromised meiotic progression beyond GVBD, further supporting the idea that prolonged inhibition of PP2A may prevent oocytes from completing meiosis. Nuclear microinjection of antiPP2A had no effect on MII development in our study. From these studies, it is unclear if nuclear anti-PP2A microinjection was capable of neutralizing the cytoplasmic PP2A following GVBD. Currently, experiments are being performed addressing the issue of antibody neutralization of PP2A following GVBD and subsequent microtubule polymerization, chromatin segregation, and normal development to MII.

Previous reports have shown that nanomolar concentrations of I2 completely abolish PP1 activity (Huang and Glinsmann, 1976; Thompson et al., 1997; Huang et al., 1999). It has been shown that I2 is present in oocytes of starfish (Pondaven and Cohen, 1987) and Xenopus (Foulkes and Maller, 1982). Research in our lab has also verified the presence of I2 mRNA and protein in mouse oocytes. Microinjection of I2 into nuclei of ROSC-arrested oocytes had no effect on GVBD. I2 is a cytoplasmic regulator of PP1 and, therefore, may not convey activity when microinjected into nuclei. This may be the result of blockage of PP1/I2 interactive sites by PP1 binding to nuclear tethering proteins or substrates. It is known that I2 binds to multiple sites on PP1 catalytic subunit (Yang et al., 2000) and only some of these interactions mediate PP1 inhibition (Connor et al., 2000). Alternatively, the dosage of I2 used may not have been sufficient to inhibit PP1 activity. Yet this alternative is unlikely since similar doses of I2 have been demonstrated to inhibit cytoplasmic PP1 activity in numerous somatic cell systems (Thompson et al., 1997; Huang et al., 1999). A nuclear inhibitor of PP1, NIPP1, has been detected in rat liver nuclei (Jagiello et al., 1995) and bovine thymus (Buellens et al., 1992). However, studies in our lab failed to identify this enzyme in fully-grown mouse GV-intact oocytes. Lack of this nuclear regulator of PP1 activity in mouse oocyte nuclei raises the question of how nuclear PP1 is regulated in mouse oocytes.

Based on results of previous experiments, purified recombinant PP1 was also injected into oocyte GV, without inhibition of $\mathrm{p} 34^{\mathrm{cdc} 2}$ kinase activity, to determine whether NE integrity could be maintained. Microinjection of active PP1 in an anaphase mitotic cell affects subsequent cell cycle activity, resulting in accelerated 
cytokinesis and reflattening of the injected cell (Fernandez et al., 1992). Failure of PP1 GV-microinjection to effect subsequent meiotic progression by preventing GVBD in our study may be due to the subsequent phosphorylated state of endogenous and injected PP1. In mitotic cells, MPF's cdc2 kinase phosphorylates PP1 on Thr 320, resulting in its inactivation (Dohadwala et al., 1994; Kwon et al., 1997). Interestingly, both PP1 and MPF move into the oocyte nucleus around the same time during meiosis (Mitra and Schultz, 1996; Smith et al., 1998a). Using Western blot analysis and confocal imaging, we found the phosphoryated state, and therefore the activity of PP1, changes during oocyte maturation. Due to the regulatory role of MPF on PP1 in mitotic cells, it is reasonable to assume the activity of MPF may have already reached levels sufficient enough to phosphorylate and, therefore, inhibit injected PP1 in the oocyte. Alternatively, amounts of PP1 injected may not have been adequate to elicit an effect. However, this is not likely, as previous studies have shown an effect of PP1 on mitotic cell cycle activity at concentrations far lower than those used in this study (Fernandez et al., 1992). In the future, it will be important to determine the developmental timing of PP1 phosphorylation and whether this phosphorylation occurs during in vivo meiotic maturation.

\section{CONCLUSIONS}

In conclusion, we report here that inhibition of oocyte nuclear PP1, through specific antibody neutralization, can overcome ROSC induced block of GVBD and meiotic resumption. This provides the first direct evidence that nuclear PP1 is involved in regulation of oocyte nuclear membrane integrity. Utilizing Western blot analysis and confocal immunocytochemistry, we also demonstrate phosphorylation of PP1 at Thr320, and therefore inactivation of PP1 at or around the time of GVBD. These results reveal a cell-cycle dependent regulatory role of PP1 in nuclear envelope dynamics and oocyte meiotic progression.

\section{ACKNOWLEDGMENTS}

The authors would like to thank Dr. Carrie CosolaSmith for critically reviewing the manuscript.

\section{REFERENCES}

Abrieu A, Doree M, Fisher D. 2001. The interplay between cyclinB-cdc2 kinase (MPF) and MAP kinase during maturation of oocytes. J Cell Sci 114:257-267.

Alexander H, Van Cauwenberge A, Tsukitani Y, Mulnard J. 1991. Pleiotropic effect of okadaic acid on maturing mouse oocytes. Development 112:971-980

Bialojan C, Ruegg JC, Takai A. 1988. Effects of okadaic acid on isometric tension and myosin phosphorylation of chemically skinned guinea pig taenia coli. J Physiol 398:81-95.

Buellens M, Van Eynde A, Stalmans W, Bollem M. 1992. The isolation of novel inhibitory polypeptides of protein phosphatase 1 from bovine thymus nuclei. Biol Chem 267:16538-16544.

Cohen P. 1989. The structure and regulation of protein phosphatases. Annu Rev Biochem 58:453-508.

Connor JH, Frederich D, Huang H, Yang J, Helps NR, Cohen PTW, Nairn AC, Depaoli-Roach A, Tatchell K, Shenolikar S. 2000. Cellular mechanisms regulating protein phosphatase-1. J Biol Chem 275 : 18670-18675.

Corson DW, Fein A. 1983. Quantitative pressure injection of picoliter volumes into Limulus ventral photoreceptor. Biophysc J 44:299-304

Dessev G, Iovcheva-Dessev C, Bischoff JR, Beach D, Goldman R. 1991. A complex containing p34cdc2 and cyclin B phosphorylates the nuclear lamin and disassembles nuclei of clam oocytes in vitro. J Cell Biol 112:523-533.

Dohadwala M, da Cuz SE, Hall F, Williams R, Carbonara-Hall D, Nairn A, Greengard P, Brandt N. 1994. Phosphorylation and inactivation of protein phosphatase 1 by cyclin dependent kinases. Proc Natl Acad Sci USA. p 6408-6412.

Eggart M, Radomski N, Linder D, Tripier D, Traub P, Jost E. 1993 Identification of novel phosphorylation sites in murine A-type lamins. Eur J Biochem 213:659-671.

Endo S, Zhou X, Connor J, Wang B, Shenolikar S. 1996. Multiple structural elements define the specificity of recombinant human inhibitor-1 as a protein phosphatase-1 inhibitor. Biochem 35:52205228.

Fernandez A, Brautigan DL, Lamb NJC. 1992. Protein phosphatase type 1 in mammalian cell mitosis: Chromosomal localization and involvement in mitotic exit. J Cell Biol 116:1421-1447.

Foulkes JG, Maller JL. 1982. In vivo actions of protein phosphatase inhibitor 2 in Xenopus oocytes. FEBS Letters 150:155-160.

Gavin AC, Tsukitani Y, Schorderet-Slatkine S. 1991. Induction of mphase entry of prophase-blocked mouse oocytes through microinjection of okadaic acid, a specific phosphatase inhibitor. Exp Cell Res 192:75-81.

Goris J, Hermann J, Hendrix P, Ozon R, Merlevede W. 1989. Okadaic acid, a specific protein phosphatase inhibitor, induces maturation and MPF formation in Xenopus laevis oocytes. FEBS Letters 245:91-94

Goss V, Hocevar B, Thompson L, Stratton C, Burns D, Fields A. 1994 Identification of nuclear beta II protein kinase $\mathrm{C}$ as a amitotic lamin kinase. J Biol chem 269:19074-19080.

Houliston E, Guilly MN, Courvalin J, Maro B. 1988. Expression of nuclear lamins during mouse preimplantation development. DevSuppl 102:271-278.

Huang FL, Glinsmann WH. 1976. Separation and characterization of two phosphorylase phosphatase inhibitors from rabbit skeletal muscle. Eur J Biochem 70:419-426.

Huang HB, Horiuchi A, Watanabe T, Shih SR, Tsay HJ, Li HC, Greengard P, Nairn AC. 1999. Characterization of the inhibition of protein phosphatase-1 by DARPP-32 and inhibitor-2. J Biol Chem 274:7870-7878.

Ingebritsen TS, Cohen P. 1983. The protein phsphatases involved in cellular regulation. Classification and substrate specificities. Eur J Biochem 132:255-261.

Jagiello I, Beullens M, Stalmans W, Bollen M. 1995. Subunit structure and regulation of protein phosphatase- 1 in rat liver nuclei $\mathrm{J}$ Biol Chem 270:17257-17263.

Kalous Jaroslav, Kubelka M, Rimkevicova Z, Guerrier P, Motlik J. 1993. Okadaic acid accelerates germinal vesicle breakdown and overcomes cycloheximide and 6-dimethylaminopurine block in cattle and pig oocytes. Dev Biol 157:448-454.

Krohne G, Dabuvalle M, Franke W. 1981. Cell type specific differences in protein composition of nuclear pore complex lamina structures in oocytes and erythrocytes of xenopus laevis. J Mol Biol 151:121141.

Kwon Y, Huang H, Desdouits F, Girault J, Greengard P, Nairn A. 1997. Characterization of the interaction between DARPP-32 and protein phosphatase 1 (PP1): DARP-32 peptides antagonize the interaction of PP1 with binding proteins. Proc Natl Acad Sci USA. p 35363634.

Labbe JC, Capony JP, Caput D, Cavadore JC, Derancourt J, Kaghad M, Lelia JM, Picard A, Doree M. 1989. MPF from starfish oocytes at first meiotic metaphase is a heterodimer containing one molecule of Cdc2 and one molecule of cyclin B. EMBO J 8:3053-3058.

Lu Q, Dunn R, Angles R, Smith G. 2002. Regulation of spindle formation by active mitogen activated protein kinase and protein phosphatase 2A during mouse oocyte meiosis. Biol Repro 66:29-37.

Maller JL. 1993. On the importance of protein phosphorylation in cell cycle control. Mol Cell Biochem 127:267-281. 
Marchal R, Tomanek M, Terqui M, Mermillod P. 2001. Effects of cell cycle dependent kinase inhibitor on nuclear and cytoplasmic maturation of porcine oocytes. Mol Rep Dev 60:65-73.

Maul G, Schatten G, Jimenez S, Carrera A. 1987. Detection of nuclear lamin $\mathrm{B}$ epitopes in oocyte nuclei from mice, sea urchins, and clams using a human autoimmune serum. Dev Biol 121:368-375.

Mermillod P, Tomanek M, Marchal R, Meijer L. 2000. High developmental competence of cattle oocytes maintained at the germinal vesicle stage for $24 \mathrm{hr}$ in culture by specific inhibition of MPF kinase activity. Mol Reprod Dev 55:89-95.

Mitra J, Schultz RM. 1996. Regulation of the acquisition of meiotic competence in the mouse: Changes in the subcellular localization of cdc2, cyclin B1, cdc25C, and wee1, and in the concentration of these proteins and their transcripts. J Cell Sci 109:2407-2415.

Nikolakaki E, Meier J, Simos G, Spyros GD, Giannakouros T. 1997. Mitotic phosphorylation of the lamin B receptor by a serine/Arginine kinase and p34 cdc2. J Biol Chem 272:6208-6213.

Ookata K, Hisanaga S, Okano T, Tachibana K, Kishimoto T. 1992. Relocation and distinct subcellular localization of p34 cdc2-cyclin b complex at meiosis reinitiation in starfish oocytes. EMBO J 11:17631772.

Pahlavan G, Polanski Z, Kalab R, Golsteyn R, Nigg EA, Maro B. 2000. Characterization of polo-like kinase 1 during meiotic maturation of the mouse oocytes. Dev Bio 220:392-400.

Peter M, Heitlinger E, Haner M, Aebi U, Nigg EA. 1991. Disassembly of in vitro formed lamin head-to-tail polymers by CDC2 kinase. EMBO 10:1535-1544.

Picard A, Capnoy JP, Brautigan dL, Doree M. 1989. Involvement of protein phosphatases 1 and $2 \mathrm{~A}$ in the control of $\mathrm{m}$ phase-promoting factor activity in starfish. J Cell Biol 109:3347-3354.

Pincus G, Enzmann EV. 1935. The comparative behavior of mammalian eggs in vivo and in vitro. I. The activation of ovarian eggs. J Exp Med 62:655-675.

Pondaven P, Cohen P. 1987. Identification of protein phosphatase 1 and $2 \mathrm{~A}$ and inhibitor 2 in oocytes of the starfish Asterias rubens and Marthasterias glacialis. Eur J Biochem 167:135-140.

Quinn P, Kerin J, Warnes G. 1985. Improved pregnancy rate in human in vitro fertilization with the use of a medium based on the composition of human tubal fluid. Fertil Steril 44:493-498.

Rime H, Huchon D, Jessus C, Goris J, Merlevede W, Zon R. 1990. Characterization of MPF activation by okadaic acid in xenopus oocytes. Cell Differ Dev 29:47-56.
Schatten G, Simerly C, Schatten H. 1985. Microtubule configuration during fertilization, mitosis, and early development in the mouse and the requirement for egg microtubule mediated motility during mammalian fertilization. Proc Natl Acad Sci USA 82:4152-4156.

Schwartz Da, Schultz RM. 1991. Stimulatory effect of okadaic acid, an inhibitor of protein phosphatases, on nuclear envelope breakdown and protein phosphorylation in mouse oocytes and one-cell embryos. Dev Biol 145:119-127.

Smith GD, Sadhu A, Mathies S, Wolf DP. 1998a. Characterization of protein phosphatases in mouse oocytes. Dev Biol 204:537-549.

Smith GD, Sadhu A, Wolf DP. 1998b. Transient exposure of rhesus macaque oocytes to calyculin-A and okadaic acid stimulated germinal vesicle breakdown permitting subsequent development and fertilization. Biol Repro 58:880-886.

Sontag E, Nunbhakdi-Craig V, Bloom GS, Mumby MC. 1995. A novel pool of protein phosphatase $2 \mathrm{~A}$ is associated with microtubules and is regulation during the cell cycle. J Cell Biol 128:1131-1144.

Steen RL, Martins SB, Tasken K, Collas P. 2000. Recruitment of protein phosphatase 1 to the nuclear envelope by A-Kinase anchoring protein AKAP149 is a prerequisite for nuclear lamina assembly. J Cell Biol 150:1251-1261.

Stuurman N, Heins S, Aebi U. 1998. Nuclear lamins: Their structure, assembly, and interactions. J Struct Biol 122:42-66.

Terasaki M, Campagnola P, Rolls MM, Stein PA, Ellenberg J, Hinkle B, Slepchenko B. 2001. A new model for nuclear envelope breakdown. Mol Biol Cell 12:503-510.

Thompson L, Fields A. 1996. Beta II protein kinase C is required for the G2/M phase transition of cell cycle. J Biol Chem 271:15045-15053.

Thompson LJ, Bollen M, Fields AP. 1997. Identification of protein phosphatase 1 as a mitotic lamin phosphatase. J Biol Chem 272: 29693-29697.

Tournebize R, Andersen SSL, Verde F, Doree M, Karsenti E, Hyman AA. 1997. Distinct roles of PP1 and PP2A-like phosphatases in control of microtubule dynamics during mitosis. EMBO J 16:55375549 .

Van Dolah FM, Ramsdell JS. 1992. Okadaic acid inhibits a protein phosphatase activity involved in formulation of the mitotic spindle of GH4 rat pituitary cells. J Cell Phsyiol 152:190-198.

Yang J, Hurley TD, DePaoli-Roach AA. 2000. Interaction of inhibitor-2 with the catalytic subunit of protein phosphatase 1(PP1): Identification of a sequence analogous to the consensus PP1-binding motif. J Biol Chem 275:22635-22644. 